\title{
Who am I?
}

\section{How compelling self-storytelling builds digital personal reputation}

\begin{abstract}
The work explores whether self-storytelling is a powerful predictor of personal reputation in a collaborative community of the sharing economy realm. By proposing that powerful self-storytelling allows an attractive positioning in respect to potential others, the paper extends the literature of brand storytelling and brand archetypes shifting the perspective to a personal level. This study adopts a qualitative-quantitative approach to investigate the meanings and stories contained in personal profile descriptions and their relation with reputation. Personal descriptions are interpreted as storytelling activities, labels/glosses that allow members to access the services of the community by facilitating personal reputation building. The findings show that powerful storytelling structures have defined phases and are crucial in reputation building when the story evolves in a metaphoric, symbolic lesson. The presence of archetypes, in particular the Sage and the Ruler, also confer reputational power to the stories. The results reveal opportunities for peer-to-peer communities, traditional companies, and social businesses. Marketers should design tools and platforms able to trigger consumers' desire to express their individuality through personal descriptions and suggest the drivers that affect reputation.
\end{abstract}

Keywords: storytelling, personal reputation, archetypes, sharing economy 


\section{Introduction}

A new, grassroots model of doing business is emerging, providing consumers with the power to get what they need and want where no transfer of ownership takes place. All over the world, people are renting rooms from strangers through Airbnb, outsourcing grocery trips to TaskRabbits, and traveling with ride-sharing service BlaBlaCar. These empowered individuals are participating in the sharing economy by beginning to function like hotels, taxis, farms, restaurants, manufacturers and other traditional business models. The sharing economy is becoming increasingly popular, and it is estimated, at the time we are writing, at more than US $\$ 15$ billion (PwC 2014). The trend is expected to increase, as consumers and firms seek to maximize efficiency in volatile economic conditions (Lamberton and Rose 2012).

The sharing economy is contingent upon one crucial factor: reputation, which is now considered a new currency for transactions in collaborative consumption platforms. Reputation is the enabling factor inherent within all sharing-sector activities. It helps to build trust in certain people and distrust in others. Because of its centrality to the success of the sharing economy, various thought leaders - entrepreneurs, social advocates, academics, investors, journalists - have opined as to how trust is established and maintained among strangers engaging in peer-to-peer transactions. Despite the topic has received attention, it still has not been theorized.

This work explores personal reputation, understanding its antecedents. The main objective is to assess whether self-storytelling is a powerful predictor of personal reputation in online communities.

The branding literature has long recognized the power of storytelling to provide meaning to the brand, and practitioners have used storytelling to enhance consumers' connections with brands (Brown, Kozinets and Sherry 2003; Escalas 2004; Megehee and 
Woodside 2010; Singh and Sonnenburg 2012; Woodside, Sood and Miller 2008). This work explores the use of storytelling tools to position oneself online, proposing that powerful selfstorytelling allows a more attractive positioning in respect to potential others. Similar to product branding, storytelling is interpreted as a means to personal reputation that helps promoting ones' uniqueness to an assumed audience. If once personal reputation was considered crucial for celebrities and politicians, online tools have allowed personal reputation to become an important marketing task for everyday people (Labrecque, Markos and Milne 2011: Shepherd 2005). In the sharing economy realm, where distinctions between producers and consumers effectively disappear, personal reputation can be considered an even more essential activity that allows empowered consumers not only to access sharing services but also to perform as businesses.

The present study analyses profile descriptions of community members in CouchSurfing, a peer-to-peer travel community, as self-storytelling activities and communication tools. While blogs (Megehee and Woodside 2010; Woodside, Sood and Miller 2008) and online reviews have been shown to be storytelling activities and powerful co-creative behaviors in online communities (Pera 2014; Singh and Sonnenburg 2012), digital individual profile descriptions have not yet been investigated in terms of storytelling, despite being a key element in, what we term, online relational communities.

\section{Foundational Theory and Principles}

Our theoretical framework is built on two research streams: (1) self-storytelling studied jointly with phases and archetypes, and (2) reputation building. Both are investigated from a personal perspective, shifting the focus from a corporate level to a personal/private one.

\section{Storytelling by a co-creative "tripteller"}


The branding literature recognizes the importance of stories for brands (Brown, Kozinets and Sherry 2003; Escalas 2004; Singh and Sonnenburg 2012; Woodside, Sood and Miller 2008). While brand owners have dominated the story content, production, and distribution (Brown, Kozinets and Sherry 2003), this is now changing due to the emergence of social media that enables users to share stories, also about themselves.

In online relational communities the member is often required to create and share his/her identity though profile descriptions. Within this information, storytelling occurs and it is proposed as means to communicate what is termed "expressive individuality" (Weinberg et al 2013). In essence it is expressing or sharing personal information about oneself, including feelings, behaviors, as well as information that may reveal beliefs, attitudes, and preferences. Expressive individuality can be used to build one's personal brand (e.g. Labrecque, Markos and Milne 2011), enhancing the connection in respect to potential others. Herzenstein, Sonenshein and Dholakia's (2011) findings support the interpretation that people use narratives strategically to manage favourable impressions.

The process by which people, stemming from a list of descriptive attributes, transform their biographies in narratives is well documented by the literature (Ahuvia 2005; Belk 1988; Bruner 2004). Self-storytelling not only helps the individual to understand him/herself but it informs others about his/her identity. Self-presentation (Goffman 1959) is contextual, based on a specific setting, such as personal web spaces (Schau and Gilly 2003), facing a definable and anticipated audience. Similar to product branding, storytelling is proposed as a means to personal reputation that helps promoting ones' uniqueness to a certain public.

To explore the key elements that constitute stories, the Phase Dynamics Theory of Travel Epiphany Behavior (Woodside 2010) informs our study. The phase dynamics consist of the following stages: a. Prequel. In this stage, some triggering event occurs and implicitly or explicitly influences a person who recognizes that something is unknown to him or her; $b$. 
Awakening. A person recognizes a journey might be necessary to complete this unknown aspect; c. Journey. The protagonist's experiences will consist of positive or negative encounters which influence memorable good times/moments that normally occur during a journey; d. Catharsis. The individual achieves a deep understanding of his or her experience that serves as the capstone of the trip. e. Post-journey storytelling. Reliving the emotional highs and lows in the story serves to deepen the experience and meaning of the journey.

In the story, the protagonist struggles because of inciting incidents and is required to manage different kinds of tensions, which can refer to internal tensions with oneself, personal tensions between people and their attitudes, and external tensions between an individual and nature, society, or the supernatural (McKee and Fryer 2003).

\section{Proposition 1: Profile descriptions of members in online relational communities are stories with defined phases and tension}

\section{Archetypes enactment}

All narratives, modern and ancient, employ archetypes in portraying characters. The Archetype Theory (Jung 1959) informs our conceptual framework, as it enables understanding the most powerful elements of a modern storyteller (Vogler 2007). Archetypes represent personifications of behaviors - characters who embody behavior patterns. An archetype is an internal mental model of a typical, generic story character to which an observer might resonate emotionally (Jung 1959). While originally Jung believed archetypes were genetically inherited, archetypes are learned conceptualizations according to the neoarchetypal theory (e.g. Mark and Pearson 2001). Whichever way it goes, the symbolic and affective importance of these story characters derives partially from the fact that they have endured for so long in the culture's literary, folkloric, and artistic history (Faber and Mayer 
past literature. In defining the archetypes we present their narrative function as a story gist.

Table 1: Archetypes (adapted from Faber and Mayer 2009)

\begin{tabular}{|c|c|c|}
\hline Archetype & Definition & Sources \\
\hline$\overline{\text { Caregiver }}$ & $\begin{array}{l}\text { Represented by caring, compassion, and } \\
\text { generosity. Commonly protective, devoted, } \\
\text { sacrificing, nurturing, and often parental. Usually } \\
\text { very benevolent, friendly, helping, and trusting. } \\
\text { Story gist: purity, nourishment, and motherly } \\
\text { warmth. }\end{array}$ & $\begin{array}{l}\text { Campbell (1949/2004), p. } 109 \\
\text { McAdams (1993), pp. 155, 157, } 208 \\
\text { Mark and Pearson (2001), p. } 210 \\
\text { Woodside, Sood and Miller (2008), p. } 114\end{array}$ \\
\hline Creator & $\begin{array}{l}\text { Represented by the innovative, the artistic, and the } \\
\text { inventive. Often non-social; perhaps a dreamer; } \\
\text { looking for novelty and beauty and an aesthetic } \\
\text { standard. Will emphasize quality (over quantity), } \\
\text { being highly internally driven. Story gist: creative } \\
\text { inspiration and the potency of imagination; } \\
\text { originality; authentic. }\end{array}$ & $\begin{array}{l}\text { Hall and Lindzey (1978), p. } 122 \\
\text { McAdams (1993), p. } 145 \\
\text { Mark and Pearson (2001), p. } 229 \\
\text { Woodside, Sood and Miller (2008), p. } 114\end{array}$ \\
\hline $\begin{array}{l}\text { Everyman/Everywo } \\
\text { man }\end{array}$ & $\begin{array}{l}\text { Represented by the working-class common person; } \\
\text { the underdog; the neighbour. Persevering, ordered, } \\
\text { wholesome; usually candid and sometimes } \\
\text { fatalistic. Often self-deprecating; perhaps cynical, } \\
\text { careful, a realistic and often disappointed } \\
\text { humanist. Story gist: teaches with empathy, } \\
\text { realism, and street smarts. }\end{array}$ & $\begin{array}{l}\text { Campbell (1949/2004), pp. 295-308 } \\
\text { Mark and Pearson (2001), p. } 166 \\
\text { Woodside, Sood and Miller (2008), p. } 114\end{array}$ \\
\hline Hero & $\begin{array}{l}\text { Represented frequently by the courageous, } \\
\text { impetuous warrior. Noble rescuer and crusader; } \\
\text { must often undertake an arduous task to "prove } \\
\text { their worth" and later become an inspiration. } \\
\text { Symbolically the "dragon slayer", the redeemer of } \\
\text { human strength. Story gist: fortitude, courage, and } \\
\text { victory; a journey and transformation. }\end{array}$ & $\begin{array}{l}\text { Campbell (1949/2004), pp. 34-36, 227-228 } \\
\text { McAdams (1993), p. 135 } \\
\text { Mark and Pearson (2001), p. } 106 \\
\text { Woodside, Sood and Miller (2008), p. } 114 \\
\text { Woodside, Sood and Muniz (2013), pp. 26-29 }\end{array}$ \\
\hline Innocent & $\begin{array}{l}\text { Represented by the pure, faithful, naive, trusting } \\
\text { childlike character. Humble and tranquil; longing } \\
\text { for happiness and simplicity. Often a traditionalist; } \\
\text { saintly; symbolizing renewal. Has the optimism to } \\
\text { take the journey. Story gist: trust, loyalty, and } \\
\text { reassurance. }\end{array}$ & $\begin{array}{l}\text { Jung (1959), pp. 158-159 } \\
\text { Campbell (1949/2004), pp. 327-328 } \\
\text { McAdams (1993), p. } 158 \\
\text { Mark and Pearson (2001), pp. 54-55 } \\
\text { Woodside, Sood and Miller (2008), p. } 114\end{array}$ \\
\hline Jester & $\begin{array}{l}\text { Represented by living for fun and amusement. A } \\
\text { playful and mischievous comedian. Usually ironic } \\
\text { and mirthful, sometimes irresponsible; a prankster. } \\
\text { Enjoys most a good time and diversion from care. } \\
\text { Story gist: humour, nonconformity, and the } \\
\text { element of surprise. }\end{array}$ & $\begin{array}{l}\text { Jung (1959), pp. 255-258 } \\
\text { McAdams (1993), p. } 171 \\
\text { Mark and Pearson (2001), p. } 197 \\
\text { Woodside, Sood and Miller (2008), p. } 114 \\
\text { Woodside, Sood and Muniz (2013), pp. 29-32 }\end{array}$ \\
\hline Lover/Siren & $\begin{array}{l}\text { Represented by the intimate, romantic, sensual, } \\
\text { and especially passionate. Seeking mainly to find } \\
\text { and give love and pleasure. Seductive and } \\
\text { delightful, but perilous-often tempestuous and } \\
\text { capricious. Often a warm, playful, erotic, and } \\
\text { enthusiastic partner. Story gist: power of attraction, } \\
\text { linked with the possibility of destruction. }\end{array}$ & $\begin{array}{l}\text { Jung (1959), pp. 28-30 } \\
\text { Campbell (1949/2004), pp. 316-318 C. S. } \\
\text { McAdams (1993), pp. 148-151 } \\
\text { Mark and Pearson (2001), pp. 179-181 } \\
\text { Woodside, Sood and Miller (2008), p. } 114 \\
\text { Megehee and Woodside (2010), pp. 610-617 }\end{array}$ \\
\hline Magician & $\begin{array}{l}\text { Represented by the physicist, the visionary, and the } \\
\text { alchemist. Seeking the principles of development } \\
\text { and how things work; a teacher, a performer or a } \\
\text { scientist. Story gist: transformation, self- } \\
\text { improvement, and self-mastery. }\end{array}$ & $\begin{array}{l}\text { Jung (1959), pp. 35-37 } \\
\text { McAdams (1993), pp. 208-209 } \\
\text { Mark and Pearson (2001), p. } 144 \\
\text { Woodside, Sood and Miller (2008), p. } 114\end{array}$ \\
\hline Ruler & $\begin{array}{l}\text { Represented by a strong sense of power and } \\
\text { control: the leader; the boss; the judge. Highly } \\
\text { influential, stubborn, even tyrannical. Maintains a } \\
\text { high level of dominance; can apply to an } \\
\text { administrator, arbiter, or a manager of others. } \\
\text { Story gist: authority, influence and domination. }\end{array}$ & $\begin{array}{l}\text { Campbell (1949/2004), pp. 319-322 } \\
\text { McAdams (1993), p. } 208 \\
\text { Mark and Pearson (2001), p. } 245 \\
\text { Woodside, Sood and Miller (2008), p. } 114\end{array}$ \\
\hline
\end{tabular}




\begin{tabular}{|c|c|c|}
\hline$\overline{\text { Sage }}$ & $\begin{array}{l}\text { Represented by a valuing of enlightenment and } \\
\text { knowledge; truth and understanding. This is the } \\
\text { expert and the counsellor, possessing wisdom and } \\
\text { acumen, perhaps a bit pretentious. Scholarly, } \\
\text { philosophical, intelligent; a mystical and } \\
\text { prestigious guide in the world. Story gist: } \\
\text { experience, advice and heritage. }\end{array}$ & $\begin{array}{l}\text { Jung (1959), pp. 125-127 } \\
\text { Campbell (1949/2004), pp. 46-47 } \\
\text { McAdams (1993), pp. 143, 208-209 } \\
\text { Mark and Pearson (2001), p. } 90 \\
\text { Woodside, Sood and Miller (2008), p. } 114\end{array}$ \\
\hline Seeker & $\begin{array}{l}\text { Represented by an independent, free-willed } \\
\text { adventurer. Seeks discovery and fulfilment. Often } \\
\text { solitary; spirited and indomitable; observer of the } \\
\text { self and environment. Constantly moving; a } \\
\text { wanderer. Story gist: needing to do it } \\
\text { "themselves", keeping moving until they find their } \\
\text { goal. }\end{array}$ & $\begin{array}{l}\text { McAdams (1993), p. } 138 \\
\text { Mark and Pearson (2001), p. } 72 \\
\text { Woodside, Sood and Miller (2008), p. } 114\end{array}$ \\
\hline Shadow & $\begin{array}{l}\text { Represented by the violent, haunted, and the } \\
\text { primitive; the darker aspects of humanity. Often } \\
\text { seen in a tragic figure, rejected; awkward, } \\
\text { desperately emotional. Can be seen to lack } \\
\text { morality; a savage nemesis. Story gist: mystery, } \\
\text { suspense, and uncertainty. }\end{array}$ & $\begin{array}{l}\text { Jung (1959), pp. 91-93 } \\
\text { Woodside, Sood and Miller (2008), p. } 114\end{array}$ \\
\hline
\end{tabular}

The use of archetypes as platforms to support brand construction is relatively recent.

The marketing literature (Holt 2004; Vincent 2002; Woodside, Sood and Miller 2008;

Zaltman 2003) proposes that when building a brand strategy there is the need to identify a relevant archetype that prime users of the brand unconsciously (and possibly consciously) desire to experience. Archetypes can be therefore used to guide brand strategy. The power of identifying a brand with one of these timeless stories is that the story already exists deep within our subconscious - it does not need to be created. The task for the brand is to simply evoke the story with cues.

Archetypes are here interpreted as story characters, prototypes of culturally important figures, that are learned and recognized implicitly, and whose mythological, symbolic and personal significance evoke emotional reactions both in the storyteller and in the listener. Specifically, the study proposes that the stories narrated in online relational communities reflect one or more archetypes. More formally,

Proposition 2: Archetypes manifest themselves in online relational communities

\section{Reputation building}

In online relational communities, reputation systems are like the recommendation 
systems used for example by Yelp or TripAdvisor. However, instead of rating products or services, participants rate each other, often using a familiar ranking system. Belk (2014) confirms that online reputation systems are a proper way to build trust in collaborative consumption contexts.

Trust is a state involving confident positive expectations about another's motives with respect to oneself in situations entailing risk. Based on the characterization of Mayer and Davis (1999), parties in transactions are assessed to be trustworthy when they (i) have the required skills, and characteristics that enable to exert influence within a specific domain, (ii) are believed to do good to trustors, setting aside an egocentric motive, (iii) are perceived to adhere to a set of principles that trustors consider important.

In online relational community trust involves both an online and an offline dimension, the first being the main planning touch point that enables further offline implementations. In the first online step, members have the necessity to present themselves as trustworthy people.

An active participant who shares his or her stories in online relational communities may expect intangible rewards in the form of higher status within the community. The high status makes transactions between strangers safer and less uncertain (Belk 2014; Masum and Tovey 2011; Sacks 2011; Solove 2007). Reputation therefore serves as the digital institution that protects community members and empowers them. By bridging storytelling and reputation we believe a powerful way to persuade the community of one's personal reputation is by telling a compelling story. Therefore we propose that:

Proposition 3: Powerful self-storytelling has a positive effect on overall personal reputation in online relational communities 
While the first two propositions will be explored with a qualitative approach, proposition three will be assessed quantitatively.

\section{Research methodology}

CouchSurfing may be included in what has been defined "Creative Tourism" (Richards 2011), interpreted as an escape route from the serial reproduction of mass cultural tourism, offering a relational form of tourism where authentic experiences are co-created between surfers and hosts.

CouchSurfing is a global community of 7 million people in more than 100,000 cities. Its members share their life, their world, and their journey without any money exchange. CouchSurfing connects travellers with a network of people willing to share in profound and meaningful ways, making travel a truly social experience (http://www.couchsurfing.com). CouchSurfing's values can be summarized in sharing, generosity, connections, happiness, tolerance, improving life and society, and of course in love for travel. The phenomenon has therefore become part of the worldwide accommodation market. In 2011, CouchSurfing has become a for-profit organisation, with revenues coming from a verification service fee.

An interpretive approach (Campbell 1975) is used to analyze natural occurring communications within members' profile descriptions, in order to make sense of the informant's own self-representation and relation with personal reputation. Within the qualitative paradigm we interpret storytelling through the Degrees-of-freedom instrument (DFA) proposed by Woodside, Sood and Miller (2008) and through the Archetypal Story Pattern Instrument (ASPI), for which we refer to Woodside, Sood and Muniz (2013). The two instruments provide a set of statements as a guide to interpret the text under analysis. These instruments were adopted to assess how well a specific review could match with the storytelling paradigm. It is a "Pattern-matching" between the theoretical propositions and 
observations in a set of data. The quantitative methodology involves Latent Class Analysis (LCA) and Shapley Value Regression (Shapley 1953; Shorrocks 2013) to assess: (i) the profiling of groups with different levels of reputation and (ii) the extent of the impact of each phase and archetype in reputation building.

\section{Results of qualitative data analysis}

The two stories that are presented below illustrate the master template for analyzing consumer self-narratives. The first refers to Ingrida's self-report, a 20 year old student from Lithuania who joined CouchSurfing in 2009. Her profile has been viewed 3,992 times. She has 31 friends and has received 48 positive reviews. Ingrida's profile description tells the story of a young university student in journalism characterized by a wondering soul. Her inquisitive nature leads her to travel to Italy so to understand firsthand the Italian economic crisis. The second story refers to Aaron's self-report, a 28 year old young Chinese academic from Oxford who joined CouchSurfing in 2008. His profile has been viewed 7,288 times. He has 239 friends and has received 117 positive reviews. Aaron's profile description narrates a story of him and a friend of his visiting a cemetery at night to pay a tribute to a young person killed in an accident. The application of the Phase Dynamic Theory of Epiphany Travel to Ingrida and Aaron's Self-Narratives is synthetized in the Appendix. Two additional profiles are included as further evidence of the set of stories that have been analyzed qualitatively and then generalized quantitatively.

\section{Analyzing a consumer self-narrative from a profile description \\ Prequel}

Ingrida explicitly and consciously experiences that something is unknown or missing in her life. She introduces herself (Who am I?) as a person with a nomadic soul, "as my last name anticipates (the name means "which way")". Her wondering and inquisitive personality 
has taken Ingrida to study Media and Cultural Studies and to explore what is happening at a global scale firsthand. A tipping point of the story is represented by the event of Italian economic crisis, which triggers conscious thinking about the opportunity to achieve a desirable end state, which relates to a first-hand understanding of the economic crisis.

While Ingrida's prequel is explicit, Aaron opens the story declaring, "It was one random late midnight years ago. You never know what is ahead of you, what life can teach you" anticipating that what he is about to narrate represents an unexpected journey, as life always is. Aaron's self-reflective account reveals a mystical journey, triggered by a Bruce Lee movie.

\section{Awakening}

Both Ingrida and Aaron recognize that a journey might be necessary to contemplate the missing or unknown aspects of their life. In the awakening phase, Ingrida begins her journey consciously asking "Who am I?". She decides to move to Italy in order to explore the authenticity of the economic crisis and she enters the Italian job market. In Aaron's story, instead, it is the plot of the movie that consciously triggers his awakening. When the main character, Bruce Lee, pays respect to his dead master, Aaron's friend invites him to go along with him and pay a tribute as well. Aaron is excited and challenged by something that needs to be understood, "I understood I had to go. He needed me. I felt the importance of such a tribute".

\section{Journey}

During the journey to enact the archetypal storyline, the consumer protagonist lives the ups and downs perceived in positives and negatives experiences. Very soon, Ingrida faces a big disappointment when her employer, who promised a three-month job, is not able to retain her because of too little work. Despite feeling let down, she doesn't waste time and, by following what she defines her inner voice, she finds "the perfect job as "animator" in a 
holiday resort". Aaron, in a more symbolic and mystical way, experiences an inciting incident that occurs in walking in the darkness in a cemetery to visit his friend's tomb, managing external tensions between himself and the supernatural. In such a symbolic environment he understands the motives of his journey, when "My friend lit a cigarette for him then told me that he (his friend) who left this world of a horrible accident because of a drunkard in a bar in his $17 s^{\prime \prime}$.

\section{Catharsis}

Sometime during, but also at the end of the journey, the protagonist experiences an epiphany - a sudden intuitive realization of the "meaning of it all". This follows not only a cognitive understanding of the experience, but a feeling of "cleansing" or renewal of self (catharsis). Ingrida, by putting all herself in the job "I enjoyed entertaining the guests, performing fire shows, learning the beautiful Italian language and making amazing friends", can experience the bridge between emotional fulfillment (enjoying and having fun on her job) and cognitive understanding, which leads to fulfillment and a deeper knowledge of "Who I am". As for Aaron, the catharsis phase relates to the deep contemplation of the starry night that allows him to feel something he had only understood rationally "Although cognitively you know you are in the middle of nowhere, but it was thanks to this serenity and beauty that a deep appreciation grew inside me".

\section{Post-Journey Storytelling}

Post-journey storytelling allows the epiphany traveler to relive and reinterpret events and outcomes in the journey. Through interpretation, Ingrida and Aaron's stories evolve in a metaphoric, symbolic story with a lesson, moral, gist. The gist can be explicitly found in Ingrida's sentence "If one faces challenges but never gives up, the possibilities are endless", and in Aaron's "Instead of love, money, fame, give me truth". 
The stories included in Ingrida and Aaron's profile descriptions are complete and include all phases. Ingrida and Aaron's personal stories enact different types of tension. Ingrida's internal tension is enacted since the beginning of her story when she understands that something is missing in her life. Ingrida has to struggle with personal forces, represented first by her parents who tried, unsuccessfully, to convince her in studying medicine. Secondly, by her Italian employer who obliged Ingrida to fight and find the necessary personal resources? Aaron's story refers, instead, to external tensions between himself and the supernatural.

Ingrida and Aaron's profile stories enable to synthetically analyze, through the ASPI instrument, the presence of two specific archetypes, the Seeker, enacted in Ingrida's profile description; and the Sage, enacted in Aaron's profile description.

\section{The Seeker archetype}

The Seeker is motivated by a powerful craving for new experiences and will do almost anything to avoid boredom and entrapment, even if it means not knowing what might be coming next. The Seeker encapsulates the openness to experiences that members fulfill through CouchSurfing offerings. Referring to Ingrida's profile description by searching for a job in Italy, undergoing her adventure in the Italian resort, and later retelling the story and choosing it as representative of her identity in her profile description, Ingrida fulfilled her Seeker archetype. This is at the core of the required "current mission" CouchSurfers are asked to describe in their profile descriptions. By declaring, "Life's too short to stay in one place. Let's travel!' Ingrida communicates her free-willed adventurer spirit, and desire to constantly move and make the most out of life by seeking out new approaches and perspectives. In describing herself, Ingrida declares she dares to be different from other people, and her adventurous soul and authenticity is how she is unique. Ingrida, instead of following the safer path of studying medicine at home within a family of doctors, is 
challenged to move to Wales and study media studies demonstrating a self-sufficient attitude and a need for freedom. Ingrida is unwilling to settle down or commit to what her parents wish for her, avoiding the support they would have provided. As a Seeker, Ingrida is excited and challenged by the opportunity to blaze a new trail. Seekers need to "do it themselves", they keep moving until they find their goal (and usually their true self too). By experiencing events firsthand, in specific going to Italy and searching for a job in a period of economic crisis, she motivates CouchSurfing community to challenge life and never give up. Ingrida's Post Journey gist "if one faces challenges but never gives up, the possibilities are endless", is her way of helping others in finding their callings.

\section{The Sage archetype}

The Sage is an explorer of truth and enlightenment, and travels far in search of knowledge, overcoming the temptation of dogma. Sage individuals are most fulfilled by finding the answers to great questions.

Aaron is a young Chinese academic at Oxford University but his academic background is not what allows him to fulfill the Sage archetype. Aaron does not suggest, in fact, a proper unbiased and rational investigative approach to truth. He takes inspiration from a Bruce Lee movie and addressing his friend's request for advice and help he undergoes a mystical journey. The story that enacts the Sage archetype is highly symbolic, compared to the "classic" objective academic reasoning (Mark and Pearson 2001). By dealing with complexity and the unknown Aaron, indeed, encapsulates the old wise man thanks to his ability of seeing patterns where others may not “When we came back, Steve didn't notice it so much, but I saw the most beautiful starry night I had ever seen (...)”. Aaron develops a deep self-reflection in light of what he discovered, "Although cognitively you know you are in the middle of nowhere, but it was thanks to this serenity and beauty that a deep appreciation grew inside me". This provides a contemplative pursuit and gives him the force of acting as a 
mentor to the community about life. Through impressing upon the community a sense of who we are and where we stand, Aaron fulfills the Sage archetype. This is, also, at the core of the required "current mission" that CouchSurfers are asked to describe in their profile descriptions. By declaring, "Flow!” Aaron communicates what Csikszentmihalyi and Csikszentmihalyi (1991) refer to the ultimate experience in harnessing the emotions in the service of learning, also conveying a dreamer dimension that confirms the typical Sage's ivory tower mentality. Such attitude of high disconnection to reality emerges also from what Aaron offers to teach the community "I can teach you mirror-writing with left-hand, how to eat 10 sunflower seeds in 5 seconds, or eat shrimps without using hand, and how to conduct a symphony while knowing little of music notations". By presenting himself as a helpful "wizard", and by motivating the CouchSurfing community to seek truth, the protagonist enacts the Sage archetype. Indeed, Aaron's Post Journey gist "Instead of love, money, fame, give me truth", represents the typical Sage's motto of the truth will set you free.

The function of the archetype is the same in each profile: conveying a meaning and telling a story.

A perfect level of matching between the personal profiles' stories and the statements belonging to the Degrees-of-freedom (DFA) proposed by Woodside, Sood and Miller (2008) and to the Archetypal Story Pattern Instrument (ASPI) proposed by Woodside, Sood and Muniz (2013) occurred independently for two judges trained in psychology who were, however, unfamiliar with the relevant literature on storytelling.

\section{Results of quantitative data analysis}

The database collected consists of reputational variables, the phases of storytelling described in the qualitative analysis, the 12 archetypes proposed by Woodside and Megehee (2010), and covariates (Gender, Age, Membership Length). 
Data were collected between May and July 2015 in UK in the CouchSurfing platform. The population contained both active members and passive members (i.e., members who are present in the platform but despite having filled the required descriptive attributes do not write any story in it). With the goal of investigating the stories, our final database contains only the active members $(n=400)$; information on passive members has not been collected. In this sense, we adopted a stratified random sampling, as it was random in the sub-population of active members. The phases and the archetypes were collected on a 2-point scale $(0=$ absent, $1=$ present $)$. One judge trained in psychology independently repeated the analysis on a randomly chosen 40 records sub-sample as a reliability check, which scored $81 \%$. The most important descriptive statistics of this final dataset are presented in Table 2. An average CouchSurfer has between 40 and 50 friends and positive references, and is endorsed by 5 other members of the community (Vouching). The Post Journey phase is the most common in profiles, being present almost half of the times (47.8\%). More than two out of three profiles (67.8\%) enact the Seeker archetype. As for the covariates, the average CouchSurfer is male $(61.8 \%)$ and has been present in the platform for just over five years.

Table 2. Descriptive statistics $(n=400)$

\begin{tabular}{llrr}
\hline Type of variable & Variable & Average & Sd \\
\hline Reputational & Number of friends & 41.1 & 70.1 \\
(dependent variable) & Number of positive references & 47.9 & 80.0 \\
& Number of profile views & 7635.8 & 11744.9 \\
& Vouching & 4.6 & 13.0 \\
\hline Phases & Prequel & 0.348 & 0.478 \\
& Awakening & 0.320 & 0.467 \\
& Journey & 0.240 & 0.428 \\
& Catharsis & 0.353 & 0.478 \\
& Post Journey & 0.478 & 0.500 \\
\hline Archetypes & Caregiver & 0.100 & 0.300 \\
& Creator & 0.023 & 0.148 \\
& Everyman & 0.060 & 0.238 \\
& Hero & 0.020 & 0.140 \\
& Innocent & 0.400 & 0.491 \\
& Jester & 0.078 & 0.268 \\
& Lover & 0.003 & 0.050 \\
& Magician & 0.005 & 0.071 \\
& Ruler & 0.043 & 0.202 \\
& Sage & 0.118 & 0.322 \\
& Seeker & 0.678 & 0.468 \\
& Shadow & 0.008 & 0.086 \\
\hline Covariates & Age & 34.2 & 11.2 \\
& Gender (male) & 0.618 & 0.487 \\
& Member for & 5.2 & 2.3 \\
\hline
\end{tabular}


Vouching is a quantitative measure used to indicate how many members of the community endorse the profile. Phases and Archetypes, along with the covariate Gender, are dummy variables ( $0=$ absent, $1=$ present)

The variable "Member for" is a proxy for the experience of the member and indicates the number of years that the member has been registered for.

As a first step, we classified the records based on reputation. By using as input variables the indicators of reputation Number of friends, Number of positive references, Number of profile views and Vouching, we run a cluster analysis to classify members based on their combined reputation level. In particular, we used Latent Class analysis (LCA), which is a statistical method for finding groups or subtypes of related cases multivariate data (for review, see Bartholomew, Knott and Moustaki 2011; Hagenaars and McCutcheon 2002). Age, Gender and Member for were considered as covariates in the model. We chose a solution based on the average weight of evidence (AWE) because this metric combines information on model fit and information on classification errors (Banfield and Raftery 1993; Celeux, Biernacki and Govaert 1997). Two groups characterize the chosen solution, the one with the lowest AWE: 224 respondents were classified as having low reputation and the remaining 176 as having high reputation. Table 3 shows the profiling of these groups for all the variables, with univariate tests for finding significant differences. It is interesting to highlight that all the phases are significantly different between groups, with the variable Post Journey that is present three times more in the highly reputed group. As for the archetypes, the Sage and the Ruler differ between the two groups. Finally, the three covariates are all significantly different: highly reputed CouchSurfers tend to be males, older than less reputed ones and with more experience, measured through the years of presence in the platform (Member for).

Table 3. Variable Distribution by Reputation

\begin{tabular}{llrrrrr}
\hline & & \multicolumn{2}{c}{ Low Reputation } & \multicolumn{2}{c}{ High Reputation } & \multicolumn{1}{c}{ T-test } \\
\cline { 3 - 5 } Type of variable & Variable & Average & Sd & Average & Sd & Sign. \\
\hline Reputational & Number of friends & 10.2 & 8.3 & 80.5 & 91.2 & $<.01$ \\
(dependent variable) & Number of positive references & 12.1 & 9.9 & 93.4 & 103.6 & $<.01$ \\
& Number of profile views & 2453.6 & 2293.3 & 14945.9 & 15312.0 & $<.01$ \\
& Vouching & 0.4 & 0.8 & 10.1 & 18.2 & $<.01$ \\
\hline Phases & Prequel & 0.268 & 0.444 & 0.444 & 0.499 & $<.01$ \\
& Awakening & 0.219 & 0.414 & 0.449 & 0.499 & $<.01$ \\
& Journey & 0.170 & 0.376 & 0.330 & 0.471 & $<.01$ \\
& Catharsis & 0.272 & 0.446 & 0.455 & 0.500 & $<.01$ \\
& Post Journey & 0.268 & 0.444 & 0.744 & 0.438 & $<.01$ \\
\hline
\end{tabular}




\begin{tabular}{|c|c|c|c|c|c|c|}
\hline \multirow[t]{12}{*}{ Archetypes } & Caregiver & 0.080 & 0.272 & 0.125 & 0.332 & .140 \\
\hline & Creator & 0.013 & 0.115 & 0.034 & 0.182 & .167 \\
\hline & Everyman & 0.076 & 0.265 & 0.040 & 0.196 & .132 \\
\hline & Hero & 0.018 & 0.133 & 0.023 & 0.150 & .731 \\
\hline & Innocent & 0.393 & 0.489 & 0.409 & 0.493 & .743 \\
\hline & Jester & 0.063 & 0.243 & 0.097 & 0.300 & .207 \\
\hline & Lover & 0.000 & 0.000 & 0.006 & 0.075 & .260 \\
\hline & Magician & 0.000 & 0.000 & 0.011 & 0.106 & .110 \\
\hline & Ruler & 0.009 & 0.094 & 0.085 & 0.280 & $<.01$ \\
\hline & Sage & 0.049 & 0.217 & 0.205 & 0.405 & $<.01$ \\
\hline & Seeker & 0.688 & 0.465 & 0.665 & 0.473 & .630 \\
\hline & Shadow & 0.000 & 0.000 & 0.017 & 0.130 & .051 \\
\hline \multirow[t]{3}{*}{ Covariates } & Age & 32.3 & 10.7 & 36.7 & 11.4 & $<.01$ \\
\hline & Gender (male) & 0.509 & 0.501 & 0.756 & 0.431 & $<.01$ \\
\hline & Member for & 4.3 & 2.1 & 6.3 & 2.1 & $<.01$ \\
\hline
\end{tabular}

As a second step, a regression analysis measures the extent of the relationship

between the independent variables and the dichotomous reputation segment (low reputation, high reputation). In order to decide which regression model is most appropriate, we assessed the extent of correlation between the independent variables with the aim to identify potential problems of multicollinearity. We adopted Spearman's rho correlation coefficient, a nonparametric measure of statistical dependence between two variables appropriate for both continuous and discrete variables, including ordinal variables. Results are presented in Table 4. 
Table 4. Spearman's rho correlations

\begin{tabular}{|c|c|c|c|c|c|c|c|c|c|c|c|c|c|c|c|c|c|c|c|c|}
\hline & $P R E$ & $A W A$ & $J O U$ & $C A T$ & $P J O$ & CAR & $C R E$ & $E V M$ & $H R O$ & $I N N$ & $J E S$ & $\mathrm{LOV}$ & $M A G$ & $R U L$ & $S A G$ & SEK & SHA & $A G E$ & GEN & $M B F$ \\
\hline Prequel (PRE) & 1.00 & & & & & & & & & & & & & & & & & & & \\
\hline Awakening (AWA) & $0.74 *$ & 1.00 & & & & & & & & & & & & & & & & & & \\
\hline Journey (JOU) & $0.57^{*}$ & $0.73^{*}$ & 1.00 & & & & & & & & & & & & & & & & & \\
\hline Catharsis (CAT) & $0.68^{*}$ & $0.79 *$ & $0.75^{*}$ & 1.00 & & & & & & & & & & & & & & & & \\
\hline Post Journey (PJO) & $0.61 *$ & $0.63^{*}$ & $0.56^{*}$ & $0.67^{*}$ & 1.00 & & & & & & & & & & & & & & & \\
\hline Caregiver (CAR) & $0.14^{*}$ & $0.13^{*}$ & $0.16^{*}$ & $0.19^{*}$ & $0.22 *$ & 1.00 & & & & & & & & & & & & & & \\
\hline Creator (CRE) & $0.10^{*}$ & $0.11^{*}$ & $0.19 *$ & $0.14 *$ & $0.13 *$ & $0.12 *$ & 1.00 & & & & & & & & & & & & & \\
\hline Everyman $(E V M)$ & -0.07 & -0.08 & 0.01 & -0.03 & -0.09 & -0.01 & 0.03 & 1.00 & & & & & & & & & & & & \\
\hline Hero $(\mathrm{HRO})$ & 0.08 & $0.13^{*}$ & $0.17 *$ & $0.16^{*}$ & $0.12 *$ & 0.01 & $0.10^{*}$ & -0.04 & 1.00 & & & & & & & & & & & \\
\hline Innocent (INN) & $0.14 *$ & $0.15^{*}$ & $0.14 *$ & $0.17^{*}$ & $0.19 *$ & 0.05 & 0.01 & $-0.10 *$ & 0.03 & 1.00 & & & & & & & & & & \\
\hline Jester (JES) & 0.02 & 0.04 & 0.03 & $0.12 *$ & 0.10 & -0.03 & 0.02 & -0.07 & 0.03 & $-0.10 *$ & 1.00 & & & & & & & & & \\
\hline Lover (LOV) & 0.07 & 0.07 & 0.09 & 0.07 & 0.05 & -0.02 & $0.33 *$ & -0.01 & -0.01 & 0.06 & -0.01 & 1.00 & & & & & & & & \\
\hline Magician (MAG) & 0.10 & $.103 *$ & 0.04 & 0.10 & 0.07 & -0.02 & $0.29 *$ & -0.02 & -0.01 & -0.06 & $0.11 *$ & 0.00 & 1.00 & & & & & & & \\
\hline Ruler (RUL) & 0.00 & -0.01 & 0.03 & -0.03 & 0.00 & -0.03 & 0.05 & 0.00 & -0.03 & $-0.15^{*}$ & -0.06 & -0.01 & -0.01 & 1.00 & & & & & & \\
\hline Sage (SAG) & 0.09 & 0.08 & $0.10^{*}$ & 0.07 & $0.23 *$ & 0.09 & $0.15^{*}$ & -0.03 & 0.00 & $-0.14 *$ & -0.08 & -0.02 & 0.08 & $0.15^{*}$ & 1.00 & & & & & \\
\hline Seeker (SEK) & 0.04 & $0.15^{*}$ & $0.15^{*}$ & $0.17^{*}$ & 0.07 & $-0.11 *$ & -0.04 & $-0.14 *$ & $0.10^{*}$ & $-0.18^{*}$ & -0.06 & 0.03 & -0.03 & -0.09 & $-0.15^{*}$ & 1.00 & & & & \\
\hline Shadow (SHA) & 0.00 & 0.00 & -0.05 & 0.00 & 0.03 & 0.07 & -0.01 & -0.02 & -0.01 & -0.07 & 0.08 & 0.00 & -0.01 & $0.13^{*}$ & 0.06 & -0.06 & 1.00 & & & \\
\hline Age (AGE) & 0.03 & 0.06 & 0.04 & 0.06 & $0.17^{*}$ & $0.16^{*}$ & -0.02 & 0.05 & -0.03 & 0.00 & -0.04 & $\mathrm{NA}$ & -0.03 & $0.19^{*}$ & $0.26^{*}$ & $-0.17^{*}$ & -0.04 & 1.00 & & \\
\hline Gender (GEN) & 0.00 & 0.01 & -0.03 & -0.02 & 0.05 & -0.03 & 0.05 & 0.07 & 0.08 & $-0.10^{*}$ & 0.00 & -0.06 & -0.02 & 0.06 & 0.06 & -0.07 & 0.01 & $0.18^{*}$ & 1.00 & \\
\hline Member for (MBF) & 0.03 & $0.13^{*}$ & 0.09 & $0.12 *$ & $0.25 *$ & 0.00 & $0.11^{*}$ & -0.06 & $0.10^{*}$ & 0.05 & 0.09 & 0.06 & 0.09 & 0.03 & $0.18^{*}$ & 0.02 & 0.05 & $0.32 *$ & 0.03 & 1.00 \\
\hline
\end{tabular}

Member for (MBF)

$p<0.05$ 
The correlation between most phases of the story is above 0.7 , suggesting multicollinearity issues. Therefore, we adopted a Shapley Value Regression (Shapley 1953) as it can handle multicollinear data and is well suited to estimate the contribution of predictors against a response variable (Lipovetsky and Conklin 2001). This methodology allows estimating the contribution of a single variable to a statistical indicator of goodnessof-fit of the adopted model, such as the R-squared (Huettner and Sunder 2012; Shorrocks 2013). Shapley Value Regression (SVR) takes into account all possible combinations of predictors and calculates the net effects of each predictor by averaging over all possible combinations of the predictors.

Formally, given a full regression model with $K$ explanatory variables $\left(x_{1}, x_{2}, \ldots, x_{K}\right)$, computing the contribution of each variable requires the estimation of all possible sub-models (considering all $K$ ! permutations of regressors):

$$
R_{j}^{2}=\frac{1}{K !} \sum_{\theta} R^{2}\left(f\left(x_{j}^{\theta}, x_{j}\right)\right)-R^{2}\left(f\left(x_{j}^{\theta}\right)\right)
$$

where $\theta$ defines any of the $K$ ! variable orderings. The marginal contribution to R-squared is given by the R-squared of the model that includes $x_{j}$ and all regressors preceding $x_{j}$ in that particular order $\left(x_{j}^{\theta}\right)$ minus the R-squared of the model that does not includes $x_{j}$. Thus, the Shapley value is the variable's average marginal contribution to R-squared over all possible orderings. As the dependent variable is binary (low reputation, high reputation), for the SVR we adopted the McFadden R-squared (1974), which is suitable for logistic regression.

The SVR decomposition of R-squared values, reported in Table 5, allows measuring the relative weight of the single variables on the variation of response variable. Three archetypes (Lover, Magician, and Shadow) were excluded from the analysis because they were almost absent in the data (see Table 2). The total R-square fit of the model is 0.424 , suggesting that the Reputation variation is reasonably well explained by the model. As SVR does not provide the direction of the impact, this was estimated through the Phi coefficient 
test of association (Yule 1912). A positive Phi coefficient indicates a positive association between the independent variable and Reputation, while a negative Phi coefficient indicates a negative association between them.

Table 5. Relative impact on Reputation via Shapley Value Regression

\begin{tabular}{llrc}
\hline Type of variable & \multicolumn{1}{c}{ Variable } & $\begin{array}{c}\text { SVR } \\
\text { coefficient }\end{array}$ & $\begin{array}{c}\text { Direction of } \\
\text { impact }\end{array}$ \\
\hline Phases & Prequel & $2.13^{*}$ & + \\
& Awakening & $3.62^{*}$ & + \\
& Journey & $1.64^{*}$ & + \\
& Catharsis & $3.05^{*}$ & + \\
& Post Journey & $34.64^{*}$ & + \\
\hline Archetypes & Caregiver & 0.31 & + \\
& Creator & 0.24 & + \\
& Everyman & 0.61 & - \\
& Hero & 0.32 & + \\
& Innocent & 0.23 & + \\
\hline & Jester & 0.4 & + \\
& Ruler & $6.55^{*}$ & + \\
& Sage & $5.11^{*}$ & + \\
& Seeker & 0.21 & - \\
\hline Covariates & Age & $2.42^{*}$ & + \\
& Gender & $11.87^{*}$ & + \\
& Member for & $26.65^{*}$ & + \\
\hline TOTAL & & 100.00 & \\
\hline$* p<0.05$ & & &
\end{tabular}

Results from Table 5 confirm the descriptive findings of Table 3 by showing how all the phases have a significant and positive impact on the level of reputation $(p<0.05)$. By adding together different coefficients it is possible to assess the overall impact of several combinations of elements. Interestingly, the Post Journey phase alone explains almost $35 \%$ of the variation of Reputation. Moving to the impact of the archetypes, the Ruler and the Sage archetypes are the ones with a positive and significant impact. All the covariates have a significant effect. Not surprisingly, the experience of the CouchSurfer with the platform plays a big role, with a $26.65 \%$ impact of the variable Member for.

To further explore the existing relations, frequency counts on the occurrence of the most relevant combinations of elements for each reputation group are presented in Table 6 . 
Table 6. Frequency counts of the most occurring combinations of phases for each reputation group

\begin{tabular}{l|ll|l} 
& $\begin{array}{l}\text { Low } \\
\text { Reputation }\end{array}$ & $\begin{array}{l}\text { High } \\
\text { Reputation }\end{array}$ & Total \\
\hline No phases & $\begin{array}{lll}144 \\
64.3 \%\end{array}$ & $\begin{array}{l}42 \\
23.9 \%\end{array}$ & $\begin{array}{l}186 \\
46.5 \%\end{array}$ \\
\hline Post Journey only & 6 & 34 & 40 \\
& $2.7 \%$ & $19.3 \%$ & $10.0 \%$ \\
\hline Prequel and Post Journey & 2 & 9 & $\begin{array}{l}11 \\
2.8 \%\end{array}$ \\
\hline All phases & $0.9 \%$ & 46 & 80 \\
& 34 & $26.1 \%$ & $20 \%$
\end{tabular}

Percentages are calculated with respect to the total of each reputation group.

More than half of the low reputed members do not present any story phase. The Post Journey phase on its own generates a dramatic impact: this condition is quite common among high reputed members and almost absent among low reputed ones, confirming the importance of such variable. The presence of both Prequel and Post Journey also tends to occur mostly in high reputed members. Finally, while the presence of all the phases is not associated per se to a highly reputed member, only $15.2 \%$ of profiles with low reputation contain all the phases of the story.

\section{Discussion}

The evidence herein supports the idea that self-storytelling generated by community members facilitates online personal reputation.

The qualitative findings support $\mathrm{P} 1$, which states that profile descriptions of members in online relational communities are stories with defined phases and tension. The information in the analyzed texts is stored, indexed, and retrieved in the form of stories. Stories were used to interpret past or anticipated experience, and were structured in a well-delineated beginning (initial event), middle (crisis or turning point), and ending (conclusion). The results confirm that the most compelling profile descriptions experienced the stages proposed by the phase dynamics theory of travel epiphany behavior (Woodside, Sood and Miller 2008).

It takes rationality but little creativity to describe oneself through a list of attributes, 
interests, using conventional arguments. However, to position oneself in an attractive and memorable way, community members need to go beyond a descriptive listing of attributes and develop, instead, storytelling skills. From the qualitative analysis it is possible to propose that powerful digital self-storytelling means being able to evoke and manage tension.

Powerful stories generally deal with the fundamental conflict between subjective expectations and cruel reality but are solved by the protagonist's determination and will power. The protagonist consumer experiences an "inciting incident", or turning point, which generates tension. The presence of this strain can be considered the main driver (Singh and Sonnenburg 2012) that encourages community's emotional involvement in the member's narrative. The tensions described in personal stories confirm corporate's categories of tension, proposed by McKee and Fryer (2003) that refer to internal, which are tension-filled conversation with oneself, personal that emerges out of the diversity between people and their attitudes, and external, which refer to a tension between an individual and nature, society, or the supernatural.

The qualitative analysis supports $\mathrm{P} 2$, which states that archetypes manifest themselves in self-storytelling. Couchsurfing members employ archetypes in portraying themselves. Through profile descriptions archetypes represent personifications of behaviors and values, embodying therefore behavior and value patterns. The personification of CourchSurfing's values is embodied by the Seeker archetype, which encapsulates the openness to experiences that members fulfill through CouchSurfing offerings. The goal of a Seeker is, in fact, to find about oneself through travel.

P3, which claims that powerful storytelling has a positive effect on overall reputation, is supported only partially. While all the 5 phases have an impact on reputation, Post Journey is the strongest in terms of R-squared contribution. The more the individual is able to communicate "a lesson learnt", the more (s)he will be able to build reputation. Expressive 
individuality builds reputation by explicitly providing a gist, a moral. The more the story can communicate a metaphoric, symbolic story, the more power the story will have to engage others. In relation to the archetype enactment, only the Sage and the Ruler archetypes confer reputational power to the stories. While the Seeker archetype appears to be crucial in the qualitative analysis and the most present in the quantitative one, it has no reputational explanatory role. One possible reason for this finding is that having a majority of Seekers (more than two thirds of the community members) reduces the possible variability in explaining reputation. The Sage and the Ruler archetypes are the ones, instead, that allow discriminating between a high-reputed and a low-reputed profile. The Sage helps people to understand their world, and is generally good in communicating a "lesson learnt" or what has been termed the Post Journey storytelling variable. Sage are intelligent, knowledgeable, and reflective members, they demonstrate the value of thinking things through and motivate others to seek the truth. A Sage will ponder a problem slowly and come up with the best solution after thinking it through completely and considering all of the possibilities. A ruler is characterized by a strong sense of power and control that enables him/her to make order out of chaos, taking responsibility for the good of others. A Ruler, by taking charge of things, is able to orchestrate complex situations, and make things work better. These are all trustworthy traits.

\section{Conclusions and implications}

Compelling self-storytelling facilitates personal reputation in online relational communities. Personal descriptions are personal in that they present the self, but they are public in that they are shared to a specific target audience. A story creates a more personal connection between the individual and community members and can enable a more attractive positioning of the individual against fellow community members. The findings suggest that, 
similarly to product reputation, personal reputation entails capturing and promoting an individual's strengths and uniqueness to a target audience (Shepherd 2005). Individuals use storytelling to highlight their positive attributes that are of value while at the same time differentiating themselves from other individuals in the marketplace (Labrecque, Markos and Milne 2011). Especially in the sharing economy, the construction of personal reputation is a key issue, as it becomes the only way to access the services. As the data suggest, compelling stories contained in profile descriptions require experiencing the stages proposed by the Phase Dynamics Theory of Travel Epiphany Behavior (Woodside, Sood and Miller 2008). This means that a profile description's story needs to have a well-delineated beginning (initial event), middle (crisis or turning point), and ending (conclusion). It includes actors engaged in actions to achieve goals, a display of the protagonist's feelings. It ends with a change in the life of a character. The more the storyteller is able to emphasize a lesson learnt (Post Journey), the more the story told will be powerful. Powerful self-storytelling also means being able to evoke and manage tension. Memorable stories generally deal, in fact, with the fundamental conflict between subjective expectations and cruel reality but are solved by the protagonist's determination and will power.

The present study expands the literature on personal branding by highlighting the selfstorytelling strategies that entail personal branding in online relational communities. The study makes three specific theoretical contributions. First, while previous studies proposed online reviews (Pera 2014) and blog's posts (Woodside 2010; Sing and Sonnenburg 2012) as stories, the results show that profile descriptions can be considered stories characterized by specific stages and tensions, and not only literal attributes regarding oneself. Second, selfpresentation through storytelling reflects the presence of archetypes. Third, compelling selfstorytelling results in personal reputation building. 
Apart from the consumer behavior perspective, the study comes with managerial implications as well. CouchSurfing is an example of the sharing economy, which, isn't just about new forms of transactions. It's about an entirely new way of thinking about consumption - one that involves individuals not as passive consumers but as active participants. Storytelling is a co-creative activity that is an example of such empowerment.

While storytelling does still not appear to be a designed and formalized marketing tool in any relational communities, we believe it could benefit individuals and organizations. First, from an individual point of view, the sharing economy is allowing individuals to perform as businesses. The individual who masters these tools will be better equipped not only in participating in the sharing economy by accessing its offers. This allows him/her to develop a more "entrepreneurial" posture that can be attractive for traditional companies willing to invest in new human resources to be appealing on the market. Second, marketers should design tools and platforms able to trigger consumers' desire to express their individuality through personal descriptions, not requiring exclusively objective attributes (demographics, profession, etc.). By providing suggestions regarding the importance of how to write a compelling conclusion, marketing's role could facilitate personal reputation building. McKee and Fryer (2003) emphasize that corporate stories should display the organization's struggle and show how problems have been overcome. The same process is present in personal storytelling, which also is structured around conflicts and their resolution.

\section{Limitations and future research}

The research focuses on a specific platform, and the validity of the findings in other communities remains to be assessed. A further line of inquiry should therefore develop the analysis to other online contexts. Also, the present study has investigated an online relational community where members use storytelling to connect to strangers, making online 
connections that then are turned into face-to-face encounters. It would be interesting to replicate this study in an online relational community where members interact with preexisting friends, turning offline relationships into online ones.

The study focused on written narratives, avoiding visual information, which is both one of the oldest and most contemporary forms of human storytelling and sense making. Future research should explore visual content sharing as well. An additional line of inquiry could investigate whether self-storytelling is strategic and intentional, i.e., self-related attributes developed according to the audience perception.

\section{References}

Ahuvia, Aron C. (2005), “Beyond the extended self: Loved objects and consumers' identity narratives" Journal of Consumer Research, 32, 1, 171-184.

Bartholomew, David J., Martin Knott, M., Irini Moustaki (2011), Latent variable models and factor analysis: A unified approach. Vol. 904. John Wiley \& Sons.

Belk, Russell (1988), “Possessions and the extended self," Journal of Consumer Research, 15, $139-168$.

Belk, Russell (2014), "You are what you can access: Sharing and collaborative consumption online”, Journal of Business Research, 67, 8, 1595-1600.

Brown, Stephen, Robert V. Kozinets, and John F. Sherry Jr. (2003), “Teaching Old Brands

New Tricks: Retro Branding and the Revival of Brand Meaning", Journal of Marketing, 67, 7, 19-33.

Bruner, Jerome (2004), “Life as a narrative”, Social Research, 71, 691-710.

Campbell, Donald (1975), ““Degrees of freedom” and the case study”, Comparative Political Studies, 8, 2, 178-193.

Campbell, Joseph. (1949/2008), The hero with a thousand faces (Commemorative ed.). Princeton, NJ: Princeton University Press. 
Celeux, Gilles, Christophe Biernacki, and Gerard Govaert (1997), Choosing models in modelbased clustering and discriminant analysis. In Joint Statistical Meetings of the American Statistical Association, Anaheim/Orange County, USA.

Csikszentmihalyi, Mihaly, and Mihaly Csikzentmihaly (1991), Flow: The psychology of optimal experience, Vol. 41. New York: HarperPerennial.

Escalas, Jennifer E. (2004), "Narrative processing: Building consumer connections to brands," Journal of Consumer Psychology, 14, 1, 168-180.

Faber, Michael A., and John D. Mayer (2009), "Resonance to archetypes in media: There's some accounting for taste," Journal of Research in Personality, 43, 3, 307-322.

Goffman, Erving (1959), The Presentation of Self in Everyday Life. New York, NY: Anchor Books, Doubleday.

Hagenaars, Jacques A., and Allan L. McCutcheon, eds (2002), Applied latent class analysis. Cambridge University Press.

Herzenstein, Michal, Scott Sonenshein, and Utpal M. Dholakia (2011), “Tell me a good story and I may lend you money: the role of narratives in peer-to-peer lending decisions," Journal of Marketing Research, 48, no SPL, 138-149.

Holt, Douglas B. (2004), How brand become icons: The principles of cultural branding. Boston: Harvard Business School Press.

Huettner, Frank, and Marco Sunder (2012), “Axiomatic arguments for decomposing goodness of fit according to Shapley and Owen values," Electronic Journal of Statistics, 6, 1239-1250.

Jung, Carl G. (1959), The archetypes and the collective unconscious. New York: Pantheon Books.

Labrecque, Lauren I., Ereni Markos, and George R. Milne (2011), “Online personal branding: processes, challenges, and implications," Journal of Interactive Marketing, 25,1, 37-50.

Lamberton, Cait Poynor, and Randall L. Rose (2012), "When is ours better than mine? A framework for understanding and altering participation in commercial sharing systems," Journal of Marketing, 76, 4, 109-125. 
Lipovetsky, Stan, and Michael Conklin (2001), “Analysis of Regression in Game Theory Approach," Applied Stochastic Models in Business and Industry, 17, 4, 319-330.

Mark, Margaret, and Carol S. Pearson (2001), The Hero and the Outlaw: Building Extraordinary Brands through the Power of Archetypes. New York: McGraw-Hill.

Masum, Hassan, Mark Tovey, and Craig Newmark, eds, (2011), The reputation society: How online opinions are reshaping the offline world. Cambridge, MA: MIT Press.

Mayer, Roger C., and James H. Davis (1999), "The effect of the performance appraisal system on trust for management: A field quasi-experiment," Journal of applied psychology, 84, 1, 123.

McAdams, Dan P. (1993), The stories we live by: Personal myths and the making of the self. New York: Guilford.

McFadden, Daniel (1974), "Conditional logit analysis of qualitative choice behavior," 105-142 in Paul Zarembka, ed., Frontiers in Econometrics. Academic Press.

McKee, Robert, and Bronwyn Fryer (2003), "Storytelling that moves people: A conversation with screen-writing coach," Harvard Business Review, 6, 51-55.

Megehee, Carol M., and Arch G. Woodside (2010), “Creating visual narrative art for decoding stories that consumers and brands tell," Psychology \& Marketing, 27, 6, 603-622.

Pera, Rebecca (2014), "Empowering the new Traveller: Storytelling as a co-creative behavior in Tourism," Current Issues in Tourism. DOI: 10.1080/13683500.2014.982520.

PwC (2014), Five key sharing economy sectors could generate $£ 9$ billion of UK revenues by 2025. Retrieved from: http://pwc.blogs.com/press_room/2014/08/five-key-sharing-economy-sectorscould-generate-9-billion-of-uk-revenues-by-2025.html. Last accessed 10/02/2015.

Richards, Greg (2011), "Creativity and Tourism, The State of the Art," Annals of Tourism Research, 38, 4, 1225-1253.

Sacks, Danielle (2011), “The sharing economy”, Fast company (April 18, online edition, http://www.fastcompany.com/1747551/sharing-economy, last accessed September 23, 2013).

Schau, Hope Jensen, and Mary C. Gilly (2003), "We Are What We Post? Self-Presentation in Personal Web Space,” Journal of Consumer Research, 30, 12, 385-404. 
Shapley, Lloyd S (1953). Additive and non-additive set functions. Princeton University. Shepherd, Ifan DH (2005), "From Cattle and Coke to Charlie: Meeting the Challenge of Self Marketing and Personal Branding," Journal of Marketing Management, 21, 5-6, 589-606.

Shorrocks, Anthony F. (2013), “Decomposition procedures for distributional analysis: a unified framework based on the Shapley value," Journal of Economic Inequality, 11, 1, 99-126.

Singh, Sangeeta, and Stephan Sonnenburg (2012), "Brand performances in social media," Journal of Interactive Marketing, 26, 4, 189-197.

Solove, Daniel J. (2007), The future of reputation: Gossip, rumor, and privacy on the Internet. New Haven, CT: Yale University Press.

Vincent, Laurence (2002), Legendary brand: Unleashing the power of storytelling to create a winning market strategy. Chicago, IL: Kaplan Business.

Vogler, Cristopher (2007), The writer's journey: Mythic structure for writers. Studio City, CA: Michael Wiese Productions.

Weinberg, Bruce D., Ko de Ruyter, Chrysanthos Dellarocas, Michael Buck, and Debbie Isobel Keeling (2013), “Destination Social Business: Exploring an Organization's Journey with Social Media, Collaborative Community and Expressive Individuality," Journal of Interactive Marketing, 27, 4, 299-310.

Woodside, Arch G. (2010), "Brand-consumer storytelling theory and research: Introduction to a Psychology \& Marketing special issue," Psychology \& Marketing, 27, 6, 531-540.

Woodside, Arch G., and Carol M. Megehee (2010), “Advancing consumer behavior theory in tourism via visual narrative art," International Journal of Tourism Research, 12, 5, 418-431.

Woodside, Arch G., Suresh Sood, and Kenneth E. Miller (2008), "When consumers and brands talk: storytelling theory and research," Psychology \& Marketing, 25, 2, 97-145.

Woodside, Arch, Suresh Sood, and Karlan Muniz (2013), "Creating and Interpreting Visual Storytelling Art in Extending Thematic Apperception Tests and Jung's Method of Interpreting Dreams," Advances in Culture, Tourism and Hospitality Research, 7, 15-45.

Yule, Udny G. (1912), "On the methods of measuring the association between two attributes," Journal of the Royal Statistical Society, 75, 579-652. 
Zaltman, Gerald (2003), How consumers think: Essential insights into the mind of the marketer.

Boston, MA: Harvard Business School Press. 


\section{Appendix: Application of Phase Dynamic Theory of Epiphany Travel to Self-Narrative}

\section{\# 70 - Ingrida's Self-Narrative from her Profile Description}

Prequel

Awakening

Journey

Catharsis

Post-Journey Storytelling
I am a girl from a town called Kelme in the middle of nowhere, Lithuania. I have a nomadic soul and even my last name suggests this as it translates to 'which way?' This time my wandering soul has brought me to Cardiff University to study Journalism, Media and Cultural Studies. Most of my family members are working in the medical profession and they have always wanted me to study medicine. No matter how much they have tried to convince me, I was determined to study media where my heart lies... ... I have been trying to understand events by experiencing them firsthand. One such event was recent economic crisis in Italy, a country stricken with unemployment.

... However my resilience soon came under heavy trial when the employer that promised me a 3-month job could not retain me due to low customer turn out to the restaurant. Without wasting time, I set out to find another job but found it difficult. I had started to feel desperate, even cancelling my summer plans had crossed my mind. However it was like a voice kept telling me not to give up. After countless failures and searching across different places, I found the perfect job. My role was to carry out animation in the tourist camping village.

I enjoyed entertaining the guests, performing fire shows, learning the beautiful Italian language and making amazing friends.

I believe that with willingness and determination help to find a perfect job. I agree the number of jobs has been reduced, but with determination and direction, any job seeker can find a job for oneself. If one faces challenges but never gives up, the possibilities are endless.

\section{\# 34 - Aaron's Self-Narrative from his Profile Description}

Prequel

Awakening

Journey

Catharsis

Post-Journey Storytelling
It was one random late midnight many years ago. You never know what is ahead of you, what life can teach you. I was with my friend Steve watching Bruce Lee movie in his house in Gettysburg, South Dakota.

In the movie the character Bruce played paid respect to his old dead master. Steve turned to me and said: I want to visit a friend and pay my respect as well, what do you think? Would you like to come along? I understood I had to go. He needed me. I felt the importance of such a tribute.

We drove out to the cemetery and finally found the spot in darkness, with a bit of fear and trepidation. My friend lit a cigarette for him then told me that he who left this world of a horrible accident because of a drunkard in a bar in his $17 \mathrm{~s}$

When we came back, I saw the most beautiful starry night I had ever seen. It was pure open field in the wild, with no buildings, no lights, no people, the sky was like piles of sapphire blue velvets mosaicked with sparkling pearls, and it felt so close to you that you can touch the stars with your fingertips, and there you can smell an obscure ocean and hear the little blurry sound of waves in the air, although cognitively you know you are in the middle of nowhere, but it was thanks to this serenity and beauty that a deep appreciation grew inside me.

How amazing it is, to be aware of all the wonderful things life and world has to offer. Never be unprepared to the strange.

I can teach you mirror-writing with left-hand, how to eat 10 sunflower seeds in 5 seconds, or eat shrimps without using hand, and how to conduct a symphony while knowing little of music notations:).

Instead of love, money and fame, give me truth.

\section{\# 345 - Sarah's Self-Narrative from her Profile Description}

Prequel I am a single mum to a wonderful son, Lewis 19yrs and 2 lovely girls, Weljah is $14 y r s$ and Abigail is 9yrs. We are a bubbly family and have lots of energy and love for anyone 
Awakening

Journey

Catharsis

Post-Journey Storytelling around us. Our perspective is one of "if it is worth doing, it is worth doing it well" - a perspective of excellence, but not an economic one, excellence in simply doing the best with what we have for the people we love.

I smile when I want to scream. I sing when I want to cry. I cry when I am happy and laugh when I am nervous. I fight! For what I believe in. I stand up to injustice. I don't take no for an answer when I believe there is a better solution. I love unconditionally. I cry when my children excel and cheer when their friends get awards. I am happy when I hear about a birth or a wedding. I am strong when I think there is no strength left. I know that a hug and a kiss can heal a broken heart. I'll drive, fly, walk, run or e-mail you to show how much I care about you. And I am what I am because of how I lived.

I woke up one morning and find out that my kids dad was leaving us, without much explanation, finance or compassion! I had to deal not only with my kids' tears and questions for months but also with coping on my own and rebuilding a suddenly chaotic life from scratch. Add to this the vital importance and complexity of parenting well, organising efficiently and resourcing the physical, emotional and spiritual needs of the little lives around me. I could have chosen to simply exist and do enough to get by... but the concept of "willingness" came to the rescue when everything within me wanted to quit! During that period I learnt how to drive in just 3 weeks out of necessity, the rest is history...

I woke up this morning and realised that I am graduating in less than 2 months... Weljah has got a place in a wonderful secondary school, a specialist sports college. Lewis is going off to college in September and Abigail is thriving as a young girl, beautiful inside out. My kids are exceptionally independent and strong warm individuals now and together we make each other laugh, and sing and cuddle one another and live life to the full, unlimited by life's limitations! I AM BLESSED! And for me this is amazing... and yes - I am still a CS addict $:$... I am in a wonderful relationship with the most amazing gentleman and we are engaged to be married:-)

... Claude and oh boy it makes a difference to be treated like a Queen:-) Claude, the kids and I still love you all on CS for the wonderful warmth and encouraging messages we receive from all over the world and It goes to show that life has seasons.

A season to cry and a season to laugh! Aha! I guess most people love us because we show the human side of our life... that's what makes us - US!!! YOU ARE WELCOME, KARIBU SANA CSURFERS

\section{\# 16 - John's Self-Narrative from his profile Description}

Prequel I am a Mature Person with a Young Heart, from Liverpool. I am a very experienced Engineer and spent 5 years in the Merchant Navy as Marine Engineer Officer. But in fact, deep down, I love being an International Socialist \& an Environmentalist.

Awakening I understood that I was looking for something different. I started travelling a lot Overland as a Hippy Hitching \& in Camper Buses. I still want to change the World, To stop Wars to live in Peace. I Love Live Music, Dancing Singing \& Enjoying Life to the Max, I have a great sense of Humour.

Journey

Catharsis I once spent 10 days living with Bedouin Arabs in the Caves at Petra in Jordan ... Slept on a pile of Straw (with the horses and camels)

Post-Journey ... Fantastic for developing an understanding of other cultures. I have become a very open person... I have met so many really interesting people who have become friends Storytelling It is so important for World harmony and to fight Racism and bigotry, for us to get to know friends in different Countries $\&$ from different Cultures... Thank you 